\title{
Comparison of two methods for in vitro multiplication of Radopholus similis and Pratylenchus brachyurus in carrot cylinders
}

\author{
Jansen R.P. Santos ${ }^{1}$, Ednalva P. Andrade ${ }^{1}$, Dilson C. Costa ${ }^{2}$, Vilmar Gonzaga ${ }^{2}$ \& Juvenil E. Cares ${ }^{1}$ \\ ${ }^{1}$ Universidade de Brasília, Instituto de Ciências Biológicas, Departamento de Fitopatologia, 70910-900, Brasília, DF, Brazil; \\ ${ }^{2}$ Embrapa Recursos Genéticos e Biotecnologia, 70849-970, Brasília, DF, Brazil
}

Author for correspondence: Juvenil E. Cares, e-mail: cares@unb.br

\begin{abstract}
The use of in vitro mass multiplication of nematodes under axenic conditions allows intensification of studies on taxonomy, biology, epidemiology and control of these pathogens. In the present study, two methods were compared for in vitro multiplication of two species of plant-parasitic nematodes, Radopholus similis and Pratylenchus brachyurus in 20, 40 and 60 day-periods. Both techniques involved the use of carrot cylinders placed in jars with lids, with water-agar in the bottom of the flasks (WA+) or without (WA-). In WA- the nematodes were treated with a $1 \%$ solution of ampicillin whilst for WA t the axenization was carried out with a solution of mercuric chloride ( $0.01 \%)$, and streptomycin sulfate $0.02 \%$. The WA+ condition was the most favorable for multiplication of both species of nematodes, resulting in a population increase of about 280 times for $R$. similis and 226 times for $P$. brachyurus in relation to the founding population of 25 individuals. For WA- a population increase of only five times after 60 days for $R$. similis and a duplication of the population after 60 days for $P$. brachyurus was obtained. Overall, the largest amount of nematodes occurred at 60 days after inoculation.
\end{abstract}

Key words: Burrowing nematode, in vitro multiplication, root lesion nematode.

The plant-parasitic nematodes Radopholus similis (Cobb, 1893) Thorne, 1949, and Pratylenchus brachyurus (Godfrey, 1929) Filipjev Stekhoven \& Schuurmans, 1941, are migratory endoparasites that develop in functional tissues of roots. Pratylenchus brachyurus, known as the root lesion nematode, belongs to the group considered to be second in economic terms to agriculture, surpassed only by the rootknot nematode, Meloidogyne (Sasser \& Freckman, 1987), while the burrowing nematode ( $R$. similis) is considered one of the most important pathogen for banana plantations (Luc \& Vilardebo, 1961). Mass multiplication of both species in vitro allows intensifying studies on taxonomy, biology, epidemiology and control of these pathogens.

For multiplication of nematodes in vitro, axenization of specimens is a key step in establishing a monoxenic culture, to avoid contamination with microorganisms. O'Bannon \& Taylor (1968) pioneered the use of carrot discs for in vitro multiplication of $R$. similis and different species of Pratylenchus. The technique was enhanced by Moody et al. (1973), allowing the extension of culture longevity and increased rate of multiplication.

Gonzaga \& Santos (2010) successfully multiplied Pratylenchus spp. in vitro by introducing modifications to the technique of Moody et al. (1973), such as improving the process of axenization and replacing the carrot discs by individual carrot cylinders of approximately $30 \mathrm{~mm}$ in length by $15 \mathrm{~mm}$ in diameter, taken from the central portion of the roots with a metal cork-borer, without adding any medium to the flasks.

From the technique developed by Marc Boisseau, cited by Villain (2000), Costa (2004) made minor adjustments, using carrot cylinders of $20 \mathrm{~mm}$ long by 15 $\mathrm{mm}$ in diam. and successfully multiplied $R$. similis. Using this technique the risk of contamination is minimized and large populations of $R$. similis are obtained and maintained for a long period of time. However, due to lack of detailed descriptions of the technique in the literature, failures are frequent among researchers trying to multiply the nematode through this technique.

The objective of this study was to attempt to further improve the in vitro multiplication of nematodes and to compare two techniques of in vitro multiplication of $R$. similis and P. brachyurus, in search for the better method for meeting the demand of inoculum for experiments with these two nematode species.

The experiments were conducted in a growth chamber from August $28^{\text {th }}$ to October $27^{\text {th }}, 2009$. The population of $P$. brachyurus used in the experiment was extracted from soybean roots from the state of Tocantins, and the population of $R$. similis originated from banana roots collected in the state of Pernambuco and was maintained in a greenhouse in banana plants cv. Grande Naine. Nematode multiplication through the two methods was performed on fresh organic carrots which were washed and immersed in a $2 \%$ sodium 
hypochlorite solution during $15 \mathrm{~min}$. Tools used in substrate preparation were sterilized and kept in aseptic conditions in a laminar flow chamber.

Two methods were tested: one involving carrot cylinders placed inside a sterile flask containing a layer of water-agar on the bottom (WA+) and the other without such a layer (WA-). In WA-, carrot cylinders were prepared according to Moody et al. (1973), with minor adaptations, as described in Gonzaga \& Santos (2010). Microcentrifuge tubes $(1.5 \mathrm{~mL})$ were used for nematode axenization, and $100 \mathrm{~mL}$ jars with caps, instead of bottles of $180 \mathrm{~mL}$ capped only with aluminum foil, for nematode multiplication, as described in Moody et al. (1973). The nematodes of each species were extracted from their hosts as described by Coolen \& D'Herde (1972), then 25 females nematodes of each species were selected under a stereo microscope and transferred with a fine needle to microtubes containing $600 \mu \mathrm{L}$ of ampicillin $1 \%$. Ten minutes later most of the ampicillin solution was drained and $200 \mu \mathrm{L}$ of sterile water was added to the tubes. Five minutes later, most of the water content in the tube was drained and replaced with $200 \mu \mathrm{L}$ of the antibiotic solution. After ten minute rest, $150 \mu \mathrm{L}$ of the antibiotic solution was removed, and the remaining 50 $\mu \mathrm{L}$ of nematode suspension was transferred with a pipette onto the surface of a carrot cylinder. For both species of nematodes, the carrot cylinders were inoculated with 25 females, and maintained in a growth chamber adjusted to $28^{\circ} \mathrm{C}$. In $\mathrm{WA}+$, a procedure similarly to that described in Villain (2000) and Costa (2004), was used. The carrots were thoroughly washed, dried, sprayed with commercial ethanol, flamed inside a laminar flow chamber, and cut with a sterile knife on the sterile surface of a cutting board into pieces $c a$. $20 \mathrm{~mm}$ long. A sterile metal cork borer was pushed through each piece of carrot and the resulting cylinders $(20 \mathrm{~mm}$ long $\times 15 \mathrm{~mm}$ diam.) were used. Glass jars $(100 \mathrm{~mL})$ containing $10 \mathrm{~mL}$ of water-agar $1 \%$ were autoclaved with their lids. After the medium hardened, the carrot cylinders were arranged to fit transversally across the diam. of each flask with sterile tools in order to remain suspended 3-4 $\mathrm{cm}$ above the WA layer at the bottom and the lids were tightly closed. The jars were left in a growth chamber at $28^{\circ} \mathrm{C}$. After 5 days each jar was inspected for possible contaminant growth and the contaminated flasks were discarded.

Twenty-five females of each nematode species were obtained as described for WA- then placed in sterile $1.5 \mathrm{~mL}$ microtubes filled with $1000 \mu \mathrm{L}$ of sterile distilled water. The microtubes were submitted to centrifugation at 3000 rpm for six minutes and the supernatant was discarded. $1 \mathrm{~mL}$ of a solution of $0.01 \%$ mercuric chloride was added to each microtube, and another centrifugation round at $3000 \mathrm{rpm}$ for six minutes was performed and once again the supernatant was discarded. Next, $1 \mathrm{~mL}$ of a solution of streptomycin sulfate $0.02 \%$ was added to each microtube followed by another centrifugation cycle (3000 rpm for six minutes) and, finally, the supernatant was removed. After axenization, the concentrated suspension of nematodes was collected with a micropipette and transferred to the surface of the carrot cylinders under aseptic conditions and the flasks were sealed with PVC film (cling film). The jars were kept in an incubator at $28^{\circ} \mathrm{C}$ in the absence of light.

The experiment design was completely randomized with four replications for each evaluation period. The experiment was evaluated 20,40 and 60 days after inoculation. At each evaluation time the nematodes were extracted from the carrot tissues as described in Coolen \& D'Herde (1972). The nematode suspension was poured through a 140 mesh sieve and the nematodes collected in a 400 mesh sieve. The walls of the jars were also washed with sterile water and these nematodes recovered in a 400 mesh sieve.

The nematode population in each sample, including eggs, was estimated by counting 3 aliquots of $2 \mathrm{~mL}$ under a stereoscopic microscope with a score board.

Data on the total number of nematodes were transformed into $\log _{10}(\mathrm{x})$ and submitted to analysis of variance, factorial, and the averages of the original data were used to quadratic polynomial regression analysis, correlating the different evaluation times and the number of nematodes with the aid of software SISVAR (Ferreira, 2008).

Contamination of the carrot samples after five days of resting period (fungi and bacteria) was of $20 \%$ in WAand of $5 \%$ for WA+. The lower level of contamination in WA+ is probably related to the fact that in this method the carrot cylinders were not in direct contact with the moisture that accumulated on the bottom of the flasks as observed in WA-. This seems to provide more adequate conditions for proliferation of contaminants. Therefore, this represents an improvement for this technique as compared with those described by O'Bannon \& Taylor (1968), Castro and Ferraz (1989a, b), Fallas \& Sarah (1994), Castillo et al. (1995) and Boisseau \& Sarah (2008). For in vitro multiplication of nematodes, with the use of carrots from conventional non-organic fields result in lower nematode populations as compared with the use of fresh organically grown carrots (Dilson C. Costa, personal observation). Results of the present work confirmed published observations on the benefit of axenization of nematodes with mercurial products, either separately or in combination with antibiotics (O'Bannon \& Taylor, 1968; Chitambar \& Raski, 1985, Castro \& Ferraz, 1989b; Sarah \& Boisseau, 2008).

There was no statistically significant difference between the two species of nematodes in the methods of multiplication. However, there were significant differences between the methods for both species of nematodes, and for the times of evaluation. A significant interaction was observed between the methods and times of evaluation (Table 1).

There was a significant positive correlation ( $\mathrm{P}$ $<0.05$ ) between the time of assessment and the number of nematodes, except for the method WA- with P. brachyurus, which was negative and non-significant. The averages 
TABLE 1 - Analysis of variance of the multiplication of Radopholus similis and Pratylenchus brachyurus by two methods of in vitro nematode multiplication

\begin{tabular}{lcc}
\hline \hline Source of variation & DF & MS $^{\mathbf{a}}$ \\
\hline Nematodes (N) & 1 & $0.003^{\mathrm{NS}}$ \\
Methods (M) & 1 & $21.353^{* *}$ \\
Times (T) & 2 & $3.487^{* *}$ \\
N x M & 1 & $0.456^{\mathrm{NS}}$ \\
N x T & 2 & $0.229^{\mathrm{NS}}$ \\
M x T & 2 & $1.036^{* *}$ \\
N x M x T & 2 & $0.364^{\mathrm{NS}}$ \\
Error & 36 & 0.112 \\
\hline CV(\%) & & 14.79 \\
General mean $^{\mathbf{b}}$ & & 1232.91 \\
\hline
\end{tabular}

${ }^{a}$ For statistical analysis the data were converted to $\log _{10}(\mathrm{x})$.

${ }^{\mathrm{b}}$ Original data, unconverted.

of the number of nematodes for the method WA+ were significantly higher than those generated by the other method at all sampling times. Twenty days after inoculation by WA + were counted on average 560 and 148 specimens of $R$. similis and P. brachyurus, respectively, whereas WA- had on average 20 and 55 nematodes. Forty days after inoculation the mean score was 503 nematodes $(R$. similis) and 470 (P. brachyurus) for WA+, and 26 and 180 nematodes, respectively, for WA-. The largest difference was seen after 60 days, where WA+ gave an average 7010 nematodes ( $R$. similis) and 5656 (P. brachyurus), while WA- gave only 49 and 109 nematodes, respectively. In the 60-day trial nematode averages were superior to the other evaluation periods for the method WA+. Regarding the method WA-, the numerical count increased from the first nematode evaluation at 20 days to the second, after 40 days. In the evaluation after 60 days there was a reduction in the number of $P$. brachyurus in relation to previously evaluated (Figure 1).

Populations of $R$. similis and of $P$. brachyurus increased in both methods of multiplication as compared with the founding population of 25 nematodes. WA+ was far more effective, with a population increase of approximately 280 times for $R$. similis and 226 times for P. brachyurus, after 60 days, while for WA- the final population after the same period was of only respectively five times and twice the size of the founding population for $R$. similis and $P$. brachyurus and although the nematode population progressively increased along the period of evaluation for $R$. similis and initially increased until the $40^{\text {th }}$ day for $P$. brachyurus, it then dropped significantly at the $60^{\text {th }}$ day of evaluation.

Sixty days after inoculation, of the carrot cylinders in the jars still had a healthy appearance with no sign of decomposition or contamination, except for one WA- jar where growth of an unidentified fungus was observed.

It is likely that WA+ was more effective for the multiplication of populations of both nematodes because the humidity inside the jars was maintained at a higher level with this method. Castro \& Ferraz (1989b) evaluated two methods for in vitro multiplication of P. brachyurus, P. zeae, R. similis, and Tylenchorhynchus sp. on carrot disks. The authors argued that the maintenance of carrot discs in Petri dishes with a layer of agar medium provided better moisture conditions for the multiplication of the nematodes and (questionably) "better aeration" than the maintenance of carrot disks in Petri dishes without agar. However, such a benefit from the presence of an agar medium might appear superfluous since Moody et al. (1973) demonstrated that simply increasing the amount of carrots used would be sufficient to maintain the necessary humidity level.

The highest final numbers of nematodes for both, $R$. similis and $P$. brachyurus in WA+ suggest that multiplication periods equal or longer than 60 days are ideal for obtaining larger populations of nematodes. Castro \& Ferraz (1989b) also obtained the largest populations of nematodes 60 days after inoculation. As carrot cylinders appeared to be in good conditions after 60 days both, in WA+ and WA-, it is likely that multiplication would still be sustained for a longer period of time. Fallas \& Sarah (1994) managed to keep population growth of $R$. similis in carrot discs for up to 75 days at $27^{\circ} \mathrm{C}$ and were able to extend it to 135 days when keeping these at $15^{\circ} \mathrm{C}$. Gonzaga \& Santos (2010) also obtaining large populations of Pratylenchus spp. 120 days after inoculation and Castillo et al. (1995) obtained large populations of $P$. thornei 100 days after inoculation.

Variability among species and populations of nematodes must be taken into account for the purpose of selection of a multiplication procedure and length of incubation. Costa (2004) working with 12 different populations of $R$. similis, found that more aggressive populations reproduced more quickly than the less aggressive populations. In an experiment to evaluate the dynamics of three populations of $R$. similis originating from Cuba, Costa Rica and Brazil, this author found that the Cuban population, for example, reached the peak of its reproductive capacity 60 days after inoculation, while the Brazilian and the Costa Rican peaked after 90 and 120 days, respectively. The population of $R$. similis used in this study was considered the most aggressive among the ones tested by Costa (2004), and a large population was yielded after 60 days with WA+. Nevertheless, Gonzaga \& Santos (2010) obtained even larger sized populations of Pratylenchus spp. during a 60-days period using a similar methodology. This may be owing to the use of a lesser prolific population of Pratylenchus in our study.

The negative and non significant correlation between time and number of nematodes for P. brachyurus in WA-, was probably due to the great variation in the number of nematodes from a flask (replication) to another, demonstrating that WA- does not support the same pattern of development among replications, which leads us to believe that WA- method is not always reliable for the multiplication of nematodes. 

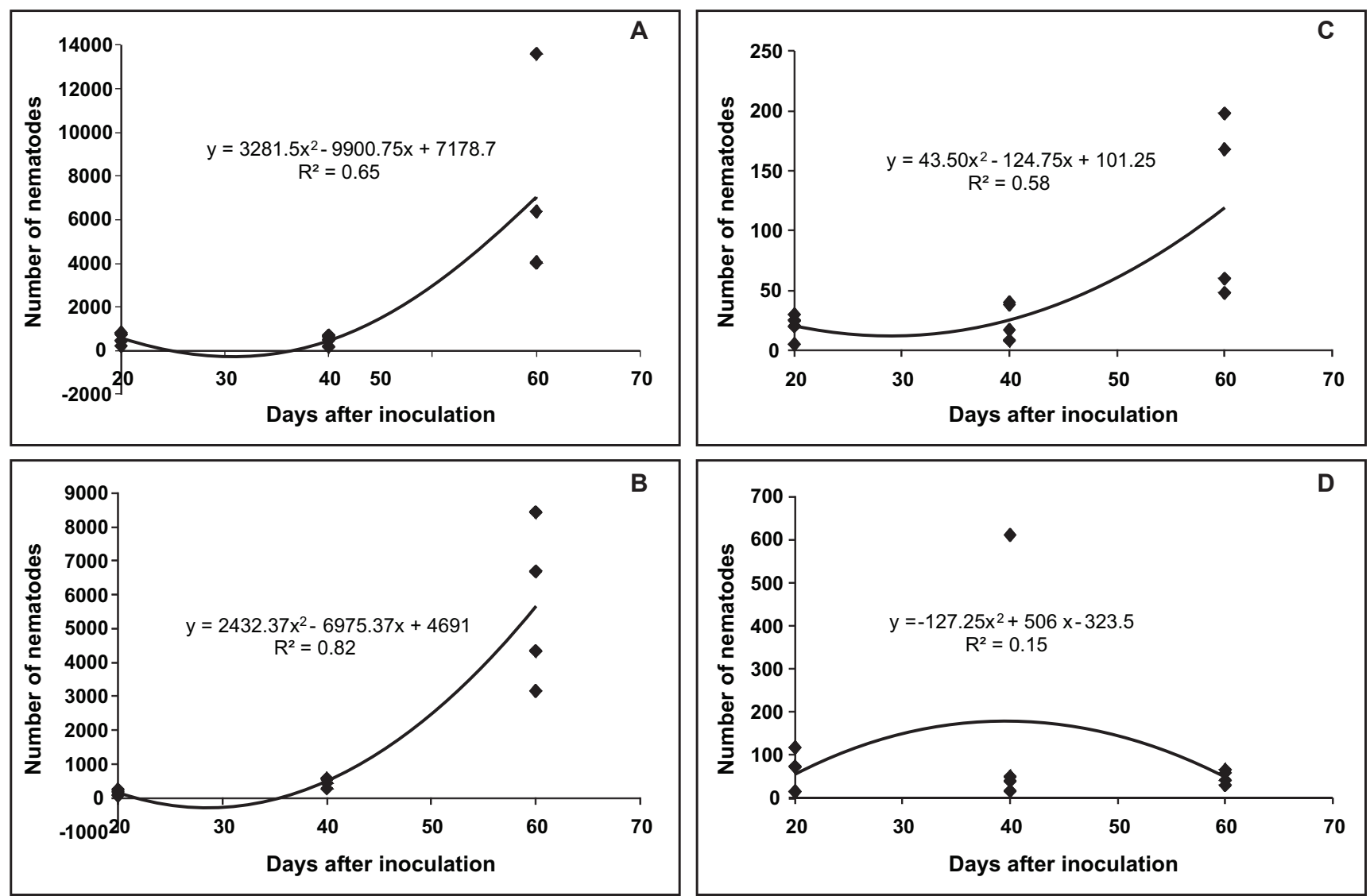

FIGURE 1 - Average number of nematodes obtained through two in vitro methods of multiplication: with a layer of water-agar (WA+) and without a layer of water-agar (WA-) for 60 days. A. Number of Radopholus similis multiplied in vitro by WA+; B. Number of Pratylenchus brachyurus obtained with the WA+ method; C. Number of Radopholus similis obtained with the WA- method; D. Number of Pratylenchus brachyurus obtained with the WA- method.

Multiplication of $P$. brachyurus and $R$. similis on carrot cylinders is a simple low cost technique, suitable for mass multiplication of nematodes for both, production of inoculum and maintenance of diverse nematode populations. Therefore, the WA+ methodology appears appropriate for the multiplication of these nematodes since it allowed the consistent production of large populations of both species of nematodes with low contamination rates of the carrot. Adjustments of the technique for different nematode species and nematode populations are recommended. Evaluations of nematode populations at shorter intervals and along longer periods of time would also lead to fine-tuning the technique in order to allow the maximum harvest of nematodes for practical use in experiments.

\section{ACKNOWLEDGEMENTS}

The Conselho Nacional do Desenvolvimento Científico e Tecnológico - CNPq is acknowledged for providing a scholarship for the first author during his Doctoral Program at the University of Brasilia and for the financial support (Proc. n. 474653/2008-0); To Fundação de Apoio à Pesquisa do Distrito Federal - FAP/DF for the financial support (Proc. n. 193.000.473/2008).

\section{REFERENCES}

Boisseau M, Sarah JL (2008) In vitro rearing of Pratylenchidae nematodes on carrot discs. Fruits 63:307-310.

Castillo P, Trapero-Casas JL, Jiménez-Díaz RM (1995) Effect of time, temperature, and inoculum density on reproduction of Pratylenchus thornei in carrot disk cultures. Journal of Nematology 27:120-124.

Castro MEA, Ferraz S (1989a) Multiplicação 'in vitro' de Pratylenchus brachyurus, P. zeae, Radopholus similis e Tylenchorhynchus sp. em discos de cenoura. Nematologia Brasileira 13:31-38.

Castro MEA, Ferraz S (1989b) Avaliação de cinco métodos de axenização para Pratylenchus brachyurus, P. zeae, Radopholus similis e Tylenchorhynchus sp. Nematologia Brasileira 13:21-30.

Chitambar JJ, Raski DJ (1985) Life history of Pratylenchus vulnus on carrot disks. Journal of Nematology 17:235-236.

Coolen WA, D'Herde CJ (1972) A method for the quantitative 
extraction of nematodes from plant tissue. Ghent (Belgium). State Nematology and Entomology Research Station.

Costa DC (2004) Variabilidade patogênica e genética de Radopholus similis em bananeira no Brasil. Tese de Doutorado, Universidade de Brasília. Brasília.

Fallas GA, Marban-Mendoza N (1994) Respuesta de tres cultivares y un hibrido de Musa a Radopholus similis en Costa Rica. Nematropica 24:161-164.

Fallas GA, Sarah JL (1994) Efecto de la temperatura de almacenamiento sobre la reproducción in vitro de Radopholus similis. Nematropica 24:175-177.

Ferreira DF (2008) SISVAR: um programa para análises e ensino de estatística. Revista Symposium 6:36-41.

Gonzaga V, Santos JM (2010). Estudo comparativo in vitro de seis espécies de Pratylenchus em cilindros de cenoura. Nematologia Brasileira 34:228-230.

Luc M, Vilardebo A (1961) Les nematodes associé aux bananiers cultives dans I'Quest African. I - Espèces parasites, dommages causes. Fruits 16:205-279.

Moody EH, Lownsbery BF, Ahmed JM (1973) Culture of rootlesion nematode Pratylenchus vulnus on carrot disks. Journal of Nematology 5:225-226.

Mountain WB (1955) A method of culturing plant parasitic nematodes under sterile conditions. Proceeding of the Helminthological Society of Washington 22:49-52.

O'Bannon JH, Taylor AL (1968) Migratory endoparasitic nematodes reared on carrot disks. Phytopathology 58:385.

Sasser JN, Freckman DW (1987). A world perspective on nematology, the role of society. In: Veech JA, Dickson DW (Eds). Vistas on Nematology. Hyattsville: Society of Nematologists, pp. 7-14.

Villain L (2000) Caractérisation et bioécologie du complexe parasitaire du genre Pratylenchus (Nemata: Pratylenchidae) présent sur caféiers (Coffea sp.) au Guatemala. Tese de Doutorado, CIRAD. Montpellier França. 